\title{
Playing with metal: fracture implants and contact sport
}

\author{
Nick A Evans, Richard O N Evans
}

\begin{abstract}
Objective-To assess the outcome of athletes returning to contact sport with indwelling fracture implants.

Method-A retrospective analysis of professional rugby union players competing in the South Wales premier league.

Results-Fifteen athletes were identified who had returned to competitive rugby union with retained fracture implants during the period 1990-97. After fracture fixation, the players resumed their preinjury level of contact sport within one to 12 months. Only two athletes suffered complications in relation to the retained implant, whereas the other 13 athletes played for up to six years without symptoms.

Conclusion-The results from this preliminary series suggest that an early return to contact sport is feasible in selected cases. Avoiding the extended delay associated with implant removal affords not only minimal disruption to competitive participation, but also prevents prolonged financial losses for the professional player.

(Br F Sports Med 1997;31:319-321)
\end{abstract}

Keywords: fracture implants; contact sport; rugby union

"When can I return to contact sport?" is a frequently asked question after fractures. There are no specific guidelines on which to base this decision, particularly if the fracture has been fixed with a metal implant. Should the implant be left in situ or removed before resuming sporting activities? The retained implant may act as a "stress riser" and place the adjacent bone at risk of a further fracture. On the othe hand, proposing implant removal enforces a prolonged absence from contact sport while bone density is restored. For the professional athlete this may constitute a significant period of unemployment.

In this preliminary study, we report the outcome of an elite group of athletes returning to contact sport with fracture implants in situ.

\section{Methods}

Athletes from six professional rugby union teams competing in the South Wales premier division provided the sample population. Current players who had sustained fractures treated with metal implants were identified through team doctors. Data were collected from the case notes and structured interviews with the athletes themselves, recording details of the implant, the date of return to competitive sport, the playing time with implant in situ, and any complications. Players who may not have resumed rugby because of their metal implant were not part of the sample population.

The use of a highly motivated group of professional athletes should minimise the influence of external factors that might otherwise cause a delay in returning to competitive sport.

\section{Results}

Fifteen players were identified who had returned to competitive rugby union with retained fracture implants. All injuries were sustained while playing rugby during the period 1990-97, and all athletes had returned to their preinjury level of performance in the premier league. We did not encounter any players who underwent fracture fixation but did not subsequently resume rugby.

Table 1 shows the details of the fracture implants and outcome, including the date of return to contact sport, complications, and the playing time with implants in situ. Coincidentally, the 15 players consisted of eight "forwards" and seven "backs", which represents a complete rugby union team.

The age range of the players was 18 to 32 years. The fractures sustained were as follows: forearm (six), ankle (four), hand (two), tibia (two), and patella (one). After fracture fixation, all 15 players returned to their previous level of competitive rugby union within one to 12 months (average return date being four months). The playing time with asymptomatic fracture implants in situ ranged from six months to six years.

On resuming sporting activities, two players suffered complications relating to the retained metal implant. The tension band wiring of a patella became painful because of its subcutaneous prominence, and had to be removed after six weeks playing time. Another player suffered a fracture alongside a radius plate after two years playing time (fig 1), which healed after cast immobilisation for four weeks. This resulted in a further 12 weeks out of competitive action.

One player who underwent forearm fixation did not resume rugby for six months, twice as long as the other forearm fractures. In this case the surgeon had advised against returning to contact sport until after the implant was removed at 12 months. However, the athlete resumed playing against medical advice after six months. 
Table 1 Details of fracture implant and outcome

\begin{tabular}{llllllll}
\hline Athlete & Age & Position & Implant & $\begin{array}{l}\text { Return date } \\
\text { (months) }\end{array}$ & Complications & $R^{*}$ & $\begin{array}{l}\text { Playing time } \\
\text { (metal in situ) }\end{array}$ \\
\hline 1 & 26 & Centre & Radius plate & 3 & No & No & 6 years \\
2 & 32 & Lock & Radius and ulna plates & 6 & No & No & 5 years \\
3 & 25 & No 8 & Radius plate & 3 & Fracture & No & 2 years \\
4 & 27 & Centre & Radius and ulna plates & 3 & No & No & 5 years \\
5 & 28 & Flank & Ulna plate & 3 & No & No & 6 months \\
6 & 25 & No 10 & Ulna plate & 2 & No & No & 6 months \\
7 & 22 & Hooker & Fibular plate & 5 & No & No & 3 years \\
8 & 23 & Flank & Fibular plate & 3 & No & No & 2 years \\
9 & 24 & Lock & Fibular plate & 4 & No & Yes & 2 years \\
10 & 32 & Wing & Fibular plate & 4 & No & No & 2 years \\
11 & 18 & Flank & Metacarpal plate & 1 & No & No & 6 months \\
12 & 26 & No 8 & Metacarpal plate & 1 & No & Yes & 6 year \\
13 & 30 & No 15 & Tibial nail & 12 & No & No & 6 weeks \\
14 & 26 & Wing & Tibial nail & 8 & No & Yes \\
15 & 23 & Centre & Patella wiring & 4 & & & \\
\hline
\end{tabular}

${ }^{\star}$ Removal of metal.

Two implants (fibular plate, tibial nail) were removed electively during the off season as advised by the supervising surgeon, and not for symptomatic reasons.

\section{Discussion}

The injured athlete may suffer on many levels including a decline in athletic conditioning, demotion in competitive ranking, and financia loss in professional sports. Not surprisingly,

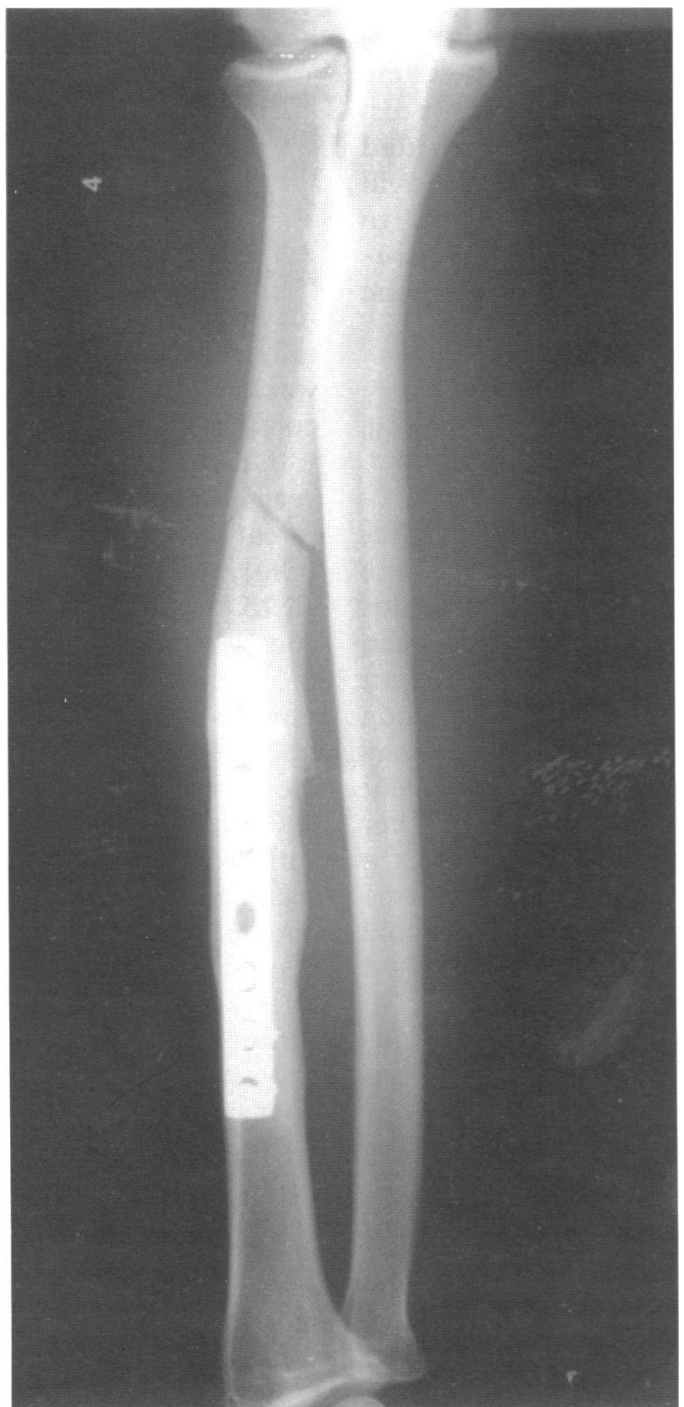

Figure 1 Fracture of proximal radius adjacent to $A O(3.5$ $\mathrm{mm}$ ) dynamic compression plate. great demands are placed on medical teams to expedite rehabilitation after injury. The question whether athletes can safely participate in contact sport with indwelling fracture implants has not been formally resolved, and answers to this important issue are long overdue. Current decision making is based on individual experience rather than published guidelines.

In terms of fracture management, contact sport players require special attention. Concern arises because the presence of a metal implant changes the local properties of bone. The difference in the modulus of elasticity between bone and metal implant results in stress shielding beneath the plate and localised osteopenia. ${ }^{1}$ There is also increased stress at the junction between normal bone and the bone/implant region. Thus, with an implant acting as a stress riser, the adjacent bone may be at increased risk of further fracture when subjected to the violent forces of contact sport. An indwelling implant may also produce local symptoms of pain and irritation because of subcutaneous prominence. Both of these complications occurred in the study group.

Removing the implant before returning to sport may seem like the obvious solution, but this imposes a prolonged delay. Bone density beneath a metal plate is restored to its prefracture level at around 18 to 21 months. ${ }^{2}$ Implant removal before this time exposes bone weakened by the presence of cortical atrophy, and is not recommended. Furthermore, residual screw holes require an additional four months for complete bone ingrowth. ${ }^{3}$ If this treatment option is advised, and the recommended protocol adhered to, then an athlete will face a two year sporting absence. Implant removal may also be complicated by neurovascular injury and refracture, particularly in the forearm. ${ }^{45}$

It is well recognised that fracture fixation expedites rehabilitation by permitting early motion, thereby minimising the joint stiffness and muscle deconditioning associated with a period of cast immobilisation. ${ }^{6}$ The results from this pilot study suggest that athletes can return to contact sport with fracture implants in situ, although refracture alongside an implant did occur in one case. It would also seem that certain implants such as tension band wires may be less compatible with contact 
sport participation, because of their subcutaneous location.

All the athletes in this study resumed contact sport within one to 12 months. This time period is dependent on the location of the fracture and the type of implant used in fixation, and is also influenced by the recommendation of the supervising surgeon. Despite the heterogeneity of the sample, the time delay is less than if implant removal was advised before participating in contact sport. If elective implant removal is required, this can be planned for the off season, allowing three to four months for residual screw holes to heal.

\section{Conclusion}

The results from this preliminary series suggest that an early return to contact sport is feasible in selected cases. A larger prospective study may in the future provide more specific guidelines on which to base fracture management decisions for these athletes, and identify the true risks. In the meantime, the results of this study should alert practitioners to the compatibility of certain fracture implants and contact sport. Avoiding the prolonged delay associated with implant removal minimises the disruption to competitive participation.

We would like to thank the orthopaedic surgeons at Morriston Hospital, East Glamorgan Hospital and Cardiff Royal Infirmary for allowing us to report on their patients. Thanks to Mr D J Pemberton for the radiograph used in figure 1 .

Richards RH, Palmer JD, Clarke NMP. Observations on removal of metal implants. Injury 1992;23:25-8.

2 Rosson JW, Petley GW, Shearer JR. Bone structure after removal of internal fixation plates. $\mathrm{f}$ Bone foint Surg $\mathrm{Br}$ 1991;73-B:65-7.

3 Rosson J, Murphy W, Tonge C, Shearer J. Healing of residual screw holes after plate removal. Injury 1991;22: 383-4.

4 Saunderson PL, Ryan W, Turner PG. Complications of metalwork removal. Injury 1992;23:29-30.

5 Rosson JW, Shearer JR. Refracture after the removal of Rosson JW, Shearer JR. Refracture after the removal of
plates from the forearm. F Bone foint Surg Br 1991;73-B: plates from.

6 Muller ME, Allgower M, Schneider R, Willenegger $H$. Manual of internal fixation. 3rd ed. Berlin: Springer-Verlag, 1991
My diabetes was diagnosed at a very difficult time in my life. I had just left school, was planning on joining the army, and was a fairly active youngster. My father was also a diabetic, however, so when told of my diagnosis, I just shrugged my shoulders. My father's life had not changed greatly and I saw no reason why mine should.

Within a few days the reality of a life of injections dawned. My mother would not let me have my breakfast until I had injected. On that morning I realised that injecting a needle into my leg would mean my skin being broken and that meant blood! It took me an hour and a half to summon up the strength to inject myself that morning. Breakfast never tasted so good! Since that morning I have had no trouble with injections.

With a career in the army derailed, my priority was to continue my ski racing career. Before my diagnosis I had finished fourth in the British Junior Ski Championships and I believed that my diabetes would not be a problem as long as I kept it in control. Although some doctors advised that it would be difficult to continue my ski racing, I decided to control my diabetes and not let it control me. With this in mind I set off to compete against the best of the world. My team mates were told that if I was looking ill I should eat a biscuit or chocolate-this soon became a reason for them to ask me for some chocolate for themselves!

With the improvement in my skiing, sugar control became more critical so I increased the frequency of blood tests. On one day, with the race delayed because of the weather, I was sitting in the restaurant awaiting my turn. I could feel my sugars rising so brought out my testing kit and began to do a test. This caused consternation among those around me. When I explained that I was doing a drug test the table rapidly cleared (random drug tests were just becoming common!)

Crossing borders caused a few funny moments during my skiing days. Arriving late one night at the Austrian/German border, I was asked by a guard whether I had my passport, followed by Green Card, other documents, where I was driving from and to, and if I had any contraband. I explained I had a bottle of whisky and two hundred cigarettes. When asked if I had any drugs, I said yes. My friend who was travelling with me looked at me in panic. Two further guards appeared and I was hauled out of the car and asked to explain. I walked round to the back of the car, opened the boot and showed him my diabetic drugs! That drama ended with two relieved skiers but rather disappointed border guards.

Diabetes is a serious matter and of course good control is important. However, we diabetics are still humans and as such life is still there to be enjoyed. Luckily I enjoy sports and so use sport to keep my B-Ms under control. I believe firmly in the fact that diabetes has taught me how to live life more healthily (even if I do have the odd hunger pang for a chocolate digestive!) and still have as much fun.

NEIL MCQUOID 